\title{
EFISIENSI BIAYA PEKERJAAN AIR CONDITIONER BERBASIS REKAYASA NILAI PADA GEDUNG PERKANTORAN
}

\section{Gian Fahmi Pangestu dan Humiras Hardi Purba}

Universitas Mercu Buana (UMB) Jakarta, Indonesia

Email: gianfahmi17@gmail.com dan humiras.hardi@mercubuana.ac.id

\section{Abstract}

The air conditioner is the most important component of a building today. Because the function of the air conditioner is to condition the air in the room of the building. Almost all buildings use the air conditioner in Indonesia. Air conditioner work has a high work weight in the Mechanical Electrical and Plumbing sub-sections. The research objective was to analyze the influence of the application of value engineering methods on the cost of air conditioning work in office buildings. This is a gap that can be examined how much the cost can be reduced for the job with the value engineering method. Without reducing the function of the air conditioner, which is to cool the room in the building. A value engineering problem that is often encountered in the field is that this method is considered a cost reduction. Where this will result in a decrease in the quality and function of the material, reduce or eliminate certain elements that have an impact on the quality reduction that violates the specified limits. One of the good values engineerings are using alternative materials that are still in the same specifications. This research focuses more on the use of value engineering in the work of air conditioner Office Buildings. By using the value engineering method, it appears that the cost efficiency that can be saved is $14.73 \%$ of the initial budget planned for the work.

Keywords: value engineering; cost efficiency; air conditioner work; office building; reduce cost; civil engineering
Abstrak
Air conditioner merupakan komponen terpenting sebuah gedung pada jaman sekarang ini. Dikarenakan fungsi air conditioner adalah mengkondisikan udara di dalam ruangan gedung tersebut. Hampir semua gedung menggunakan air conditioner di Indonesia. Pekerjaan air conditioner memiliki bobot pekerjaan yang tinggi dalam sub bagian pekerjaan Mekanikal Elektrikal dan Plumbing. Tujuan penelitian untuk menganalisis besarnya pengaruh penerapan metode rekayasa nilai terhadap biaya pekerjaan air conditioner Pada Gedung Perkantoran. Hal ini menjadi sebuah celah yang bisa di teliti seberapa besar biaya yang bisa di kurangi terhadap pekerjaan tersebut dengan metode Rekayasa Nilai. Tanpa mengurangi fungsi dari air conditioner tersebut yaitu mendinginkan ruangan yang ada di dalam gedung. Permasalahan rekayasa nilai atau value engineering yang sering dijumpai dilapangan yaitu metode tersebut lebih dianggap sebagai pengurangan biaya (cost reduction). Dimana hal ini akan mengakibatkan penurunan terhadap kualitas serta fungsi dari

$\begin{array}{ll}\text { How to cite: } & \text { Pangestu, Gian Fahmi., Humiras Hardi Purba (2021) Efisiensi Biaya Pekerjaan Air Conditioner Berbasis } \\ & \text { Rekayasa Nilai pada Gedung Perkantoran. Syntax Literate. 6(5). http://dx.doi.org/10.36418/syntax- } \\ & \text { literate.v6i5.1935 } \\ & 2548-1398 \\ \text { E-ISSN: } & \text { Ridwan Institute }\end{array}$


material tersebut, mengurangi atau menghilangkan unsur tertentu yang berdampak pada menurunya kualitas melanggar batas ketentuan spesifiksi. Rekayasa nilai yang baik salah satunya yaitu menggunakan alternative material yang masih dalam spesifikasi yang setara. Pada penelitian ini lebih memfokuskan kepada penggunaan rekayasa nilai pada pekerjaan air conditioner Bangunan Perkantoran. Dengan menggunakan metode rekayasa nilai, terlihat bahwa efisiensi biaya yang dapat dihemat sebesar $14,73 \%$ dari anggaran awal yang direncanakan untuk pekerjaan tersebut.

Kata Kunci: rekayasa nilai; efisiensi biaya; pekerjaan air conditioner; bangunan kantor,

\section{Pendahuluan}

Apabila suhu udara sedang panas, pendingin ruangan atau yang disebut air conditioner banyak digunakan demi terciptanya lingkungan yang bersuhu sejuk. Sekarang penggunaan air conditioner di Perkantoran dan Perumahan semakain banyak seiring dengan meningkatnya permintaan serta daya beli masyarakat. Kondisi tersebut berdampak terjadinya masalah baru karena semakin banyak air conditioner digunakan maka akan semakin banyak pula energi listrik yang diperlukan. Salah satu perusahaan listrik di India menyalahkan penggunaan air conditioner sebagai akibat dari tingginya pengunaan listrik di negara tersebut. Menurut IHS Markit's Home Appliance Intelligence Service pada 2016 terdapat 130 juta unit air conditioner digunakan di seluruh dunia. Setahun kemudian bertambah menjadi 160 juta unit.

Menurut Deutsche Gesellschaft für Internationale Zusammenarbeit (GIZ). Dengan dihilangkannya subsidi listrik untuk sebagian besar kelas tarif pelanggan, maka biaya energi juga akan semakin meningkat sehingga dapat membuat pemilik bangunan untuk melakukan upaya-upaya efisiensi energi (EE). Akan tetapi, sebagian besar masyarakat/individu yang terlibat dalam perencanaan, investasi, operasi dan maintenance sistem air conditioner di gedung masih belum mengetahui cara penghematan dari instalasi peralatan Refrigerasi dan Tata Udara (Refrigeration and Air Conditioning RAC) yang hemat energy.

Air conditioner merupakan komponen terpenting sebuah gedung pada jaman sekarang ini. Dikarenakan fungsi air conditioner adalah mengkondisikan udara di dalam ruangan gedung tersebut. Hampir semua gedung menggunakan air conditioner di Indonesia. Pekerjaan air conditioner memiliki bobot pekerjaan yang tinggi dalam sub bagian pekerjaan Mekanikal Elektrikal dan Plumbing. Hal ini menjadi sebuah celah yang bisa di teliti seberapa besar biaya yang bisa di kurangi terhadap pekerjaan tersebut dengan metode Rekayasa Nilai. Tanpa mengurangi fungsi dari air conditioner tersebut yaitu mendinginkan ruangan yang ada di dalam gedung.

Permasalahan rekayasa nilai atau value engineering yang sering dijumpai dilapangan yaitu metode tersebut lebih dianggap sebagai pengurangan biaya (cost reduction). Dimana hal ini akan mengakibatkan penurunan terhadap kualitas serta fungsi dari material tersebut, mengurangi atau menghilangkan unsur tertentu yang berdampak pada menurunya kualitas (melanggar batas ketentuan spesifiksi). Rekayasa nilai yang 
baik salah satunya yaitu menggunakan alternative material yang masih dalam spesifikasi yang setara. Pada penelitian ini lebih memfokuskan kepada penggunaan rekayasa nilai pada pekerjaan air conditioner Bangunan Perkantoran.

Penelitian ini akan membahas analisis biaya air conditioner tanpa mengorbankan fungsi utamanya. Pekerjaan air conditioner memiliki bobot kerja yang tinggi pada sub bagian Mekanikal Elektrikal dan Pelumbing sehingga berkesempatan besar untuk mereduce biaya pada sub pekerjaan MEP, oleh karena itu penting untuk dilakukan penelitian menggunakan metode Rekayasa Nilai untuk mendapatkan berapa biaya yang bisa di kurangi dari pekerjaan air conditioner Tersebut. Dampak penerapan metode rekayasa nilai pada pekerjaan air conditioner perlu ditinjau. Dengan menggunakan metode value engineering diharapkan dapat menghemat biaya pengerjaan air conditioner. Namun demikian, diperlukan tahapan proses dalam metode ini, sehingga dapat diputuskan untuk memilih material dan desain ducting yang tepat.

Rekayasa Nilai merupakan salah satu proses pembuatan keputusan berbasis multi disiplin yang sistematis dan terstruktur. Menganalisis suatu fungsi untuk mencapai nilai terbaik (best value) suatu proyek dengan mendefinisikan semua fungsi-fungsi yang diperlukan untuk mencapai suatu nilai atau value yang diinginkan dan menyediakan fungsi-fungsi tersebut dengan biaya yang optimum, konsisten dengan kualitas dan kinerja yang dipersyaratkan (Ariadi, 2017).

Bab ini berisi tentang penjelasan maksud dan tujuan prinsip-prinsip nilai yang dikembangkan oleh Lawrence D. Miles pada tahun 1940 dari perusahaan Generic Electric, untuk mengatasi masalah kurangnya material produk yang akan diproduksi selama Perang Dunia Kedua. Namun dalam perkembangannya, metode ini diadopsi dan diterapkan pada bidang konstruksi dan penerapan nilai-nilai keteknikan pada pekerjaan proyek (Berawi et al., 2014)

Suatu usaha yang terstruktur secara sistematis dan menerapkan sebuah teknik yang telah diakui, yaitu teknik mengidentifikasikan fungsi produk atau jasa yang memiliki tujuan memenuhi fungsi yang diperlukan dengan harga yang terendah (Save Standard, 2008). Metode yang dikembangkan oleh Lawrence D. Miles, 1947 dikenal sebagai value analysis Technique dan menjadi metode standar Perusahaan General Electric bagi studi untuk meningkatkan nilai (Marzuki, 2006).

Setelah sistem analisis nilai ini diketahui, kemudian mulai digunakan dalam proses produksi di perusahaan lain dan kemudian metode ini berkembang tidak hanya untuk menganalisis produk jadi tetapi juga untuk mencari ystem (engineering) agar produk tersebut dibuat atau lebih baik. Dikenal sebagai metode rekayasa nilai. value engineering (VE) merupakan metode yang muncul karena banyaknya biaya yang tidak diperlukan dalam suatu rencana proyek, dalam metode evaluasi value engineering (VE) digunakan untuk menganalisis sumber daya proyek, dimana dicari alternatif baru untuk menghasilkan lebih banyak. Hemat biaya dan waktu serta efektif sehingga akan meningkatkan keuntungan dan pendapatan bagi kontraktor dan pemilik (Husin, 2015).

Menurut (ASHRAE, 2016), definisi air conditioner dibuat oleh Wilson (1908). Definisi tersebut diklaim oleh Willis Carrier, "Bapak air conditioner": (a) Menjaga 
kelembaban yang sesuai di dalam kendaraan atau ruangan, (b) Menyediakan ventilasi yang konstan dan memadai, (c) Lepaskan kelembaban berlebih di udara selama waktu tertentu musim, (d) Menghilangkan mikro-organisme dari udara secara efisien seperti debu, jelaga, dan benda asing lainnya, (e) Mendinginkan udara dalam ruangan secara efisien selama musim tertentu, (f) Peralatan yang tidak mahal dalam pembelian atau pemeliharaan (Priyanto et al., 2017). Komponen pada air conditioner dibagi menjadi empat komponen yaitu komponen utama, komponen pendukung, kelistrikan, dan refrigeran. Penjelasanya sebagai berikut: Kondensor, Kompresor, Evaporator, Pipa Kapiler, Komponen Pendukung, Komponen Listrik, Refrigerant.

Fungsi air conditioner: Mengatur Suhu Udara Fungsi utama air conditioner yaitu mengkondisikan suhu dan kelembapan udara suatu ruangan. Suhu yang diinginkan tentukan dengan angka pada remote; Mengatur Kelembapan Udar Suhu dan kelembapan udara saling berhubungan. air conditioner juga berfungsi mengatur kelembapan. Kelembapan yang ideal berada pada suhu air conditioner yang ideal yaitu pada suhu 24 - 27 derajat Celsius, semakin dingin suhu makan kelembapannya semakin tinggi; Membersihkan Udara air conditioner dilengkapi dengan filter untuk menyaring debu pada udara sehingga menjadi bersih dan sehat. filter air conditioner harus dibersihkan secara rutin untuk membuang debu dan kotoran yang menempel sehingga udara bisa terjaga kesejukan dan kebersihannya (Salamadian, 2020).

Setiap air conditioner memiliki kompresor di dalamnya. Fungsi kompresor adalah untuk memampatkan dan memompa gas pendingin. Saat kompresor mengompres gas refrigeran menghasilkan panas. Untuk melarutkan panas ini, refrigeran terkompresi dipompa ke kondensor tempat kipas menghembuskan panas ke luar. Gas refrigeran berubah menjadi cairan selama proses ini. Kemudian, refrigeran cair dipompa ke katup ekspansi. Katup ekspansi memiliki sensor suhu terhubung yang berfungsi korelasi dengan pengaturan termostat. Kemudian, katup ekspansi melepaskan ke evaporator yang terdiri dari pendinginan (Prasetio et al., 2017).

Dalam proses ini, refrigeran cair menjadi bentuk gas. Transformasi dari cairan menjadi gas menyebabkan pendinginan karena energy diserap oleh sekitarnya. Kipas angin bertiup lewat melalui sirip yang menempel pada gulungan. Udara menjadi lebih dingin dan menyebar. Refrigeran berbentuk gas di kumparan pendingin kemudian pergi ke kompresor dan dikompresi sekali lagi. Siklus itu terus berlanjut kecuali kompresor dimatikan (Talal, 2016). 
Gian Fahmi Pangestu dan Humiras Hardi Purba

Tabel 1.

Research Novelty

\begin{tabular}{|c|c|c|c|c|c|c|c|c|c|}
\hline \multirow{3}{*}{$\begin{array}{c}\text { METODE BIAYA } \\
\text { KONSTRUKSI }\end{array}$} & \multicolumn{7}{|c|}{ TAHAPAN PEKERIAAN KONSTRUKSI } & \multirow{3}{*}{$\begin{array}{c}\text { JENIS } \\
\text { BANGUNAN }\end{array}$} & \multirow{3}{*}{$\begin{array}{l}\text { KINERJA } \\
\text { PROYEK }\end{array}$} \\
\hline & \multirow{2}{*}{ Struktur } & \multicolumn{3}{|c|}{ Arsitektur } & \multicolumn{3}{|c|}{ MEP } & & \\
\hline & & Lantai & Atap & Façade & Electrical & Plumbing & AC & & \\
\hline Least Cost & $\begin{array}{c}\text { Blackler, } \\
2009\end{array}$ & $\begin{array}{c}\text { Bhargava, } \\
2010\end{array}$ & Collin, 2015 & $\begin{array}{c}\text { Pingbo } \\
\text { Tang, } 2010\end{array}$ & $\begin{array}{c}\text { Blechinger, } \\
2018\end{array}$ & - & - & General & \multirow{7}{*}{$\begin{array}{l}\mathrm{C} \\
0 \\
\mathrm{~S} \\
\mathrm{~T}\end{array}$} \\
\hline $\begin{array}{l}\text { Earned Value } \\
\text { Method (EVM) }\end{array}$ & Bosch, 2015 & $\begin{array}{c}\text { Adewale, } \\
2018\end{array}$ & Anbari,2003 & \begin{tabular}{|c|} 
Sungwoo \\
Moon, 2015 \\
\end{tabular} & - & $\begin{array}{c}\text { Ghasabeh, } \\
2008\end{array}$ & - & General & \\
\hline $\begin{array}{c}\text { Cost } \\
\text { Management }\end{array}$ & $\begin{array}{c}\text { Daloisio, } \\
2017\end{array}$ & Yong, 2018 & Mir, 2014 & Lee, 2014 & Zhang, 2018 & - & - & General & \\
\hline $\begin{array}{l}\text { Software, } \\
\text { System, } \\
\text { Computation }\end{array}$ & & & & & & & $\begin{array}{c}\text { (Park et al., } \\
\text { 2020), } \\
\text { (Pazhoohesh \& } \\
\text { Zhang, 2018), (Al } \\
\text { Sulaiman, 2018) }\end{array}$ & General & \\
\hline \multirow{3}{*}{$\begin{array}{c}\text { Value } \\
\text { Engineering (VE) }\end{array}$} & \multirow{3}{*}{$\begin{array}{c}\text { Conte et all, } \\
2017\end{array}$} & \multirow{3}{*}{ Bedian, 2015} & \multirow{3}{*}{ - } & \multirow{3}{*}{$\begin{array}{c}\text { Pratama } \\
2019\end{array}$} & $\begin{array}{c}\text { Geniyu, } \\
2018\end{array}$ & - & Chantrasa, 2016 & $\begin{array}{c}\text { (Industrial } \\
\text { Product) }\end{array}$ & \\
\hline & & & & & - & - & Jiayou, 2009 & Villa & \\
\hline & & & & & - & - & My Research & Office & \\
\hline
\end{tabular}

Air conditioner memiliki beberapa tipe yang bisa digunakan untuk berbagai aplikasi. Untuk memilih jenis yang tepat air conditioner tergantung pada beberapa faktor seperti ukuran area yang akan didinginkan, dan panas total dihasilkan di dalam area tertutup. Yang biasa jenis komersial dari sebuah air conditioner menurut (Prasetio et al., 2017), adalah sebagai berikut: (a) AC jendela, (b) AC Split, (c) AC paket, (d) AC sentral.

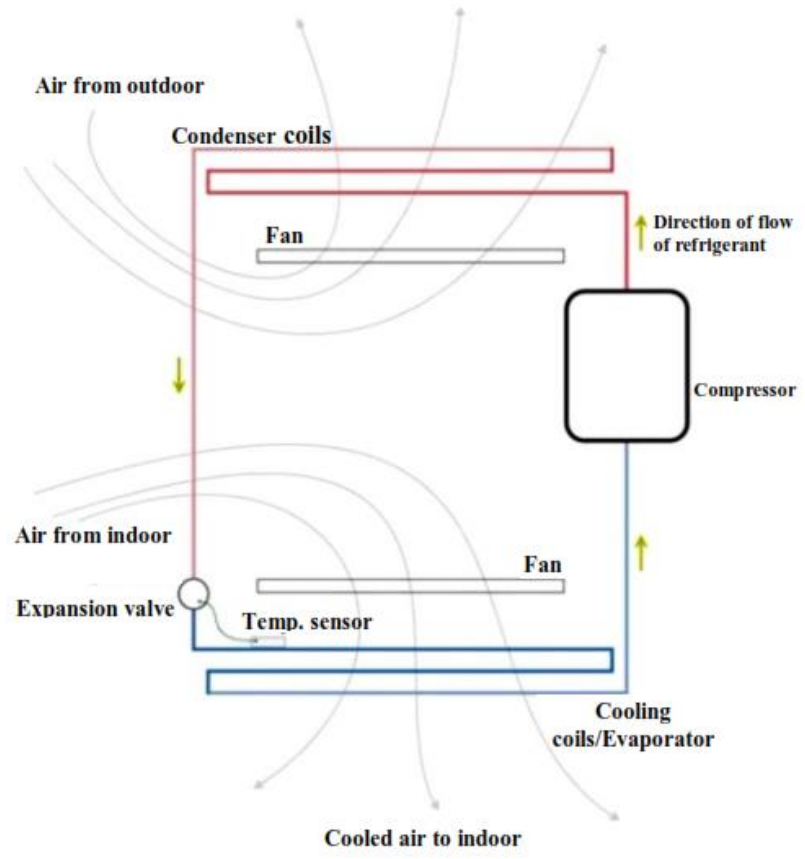

Gambar 1

Cara kerja Air Conditioner

Sumber: (Che Mat, 2004) 


\section{Metode Penelitian}

Metodologi penelitian yang digunakan dalam penulisan ini membahas secara lebih jelas penelitian, variabel penelitian, instrumen penelitian mulai dari jenis dan sumber data, teknik pengumpulan data, populasi dan sampel, metode penelitian analitik, dan jadwal pelaksanaan penelitian digunakan untuk menyelesaikan masalah. dalam penelitian. Metode penelitian menurut (Sugiyono, 2013) pada dasarnya merupakan cara ilmiah untuk memperoleh data yang valid untuk menemukan, membuktikan, dan mengembangkan suatu ilmu sehingga hasilnya dapat digunakan untuk memahami, memecahkan dan mengantisipasi masalah. Penelitian dilakukan untuk menganalisa pemahaman dan mengkaji pengaruh penerapan Rekayasa Nilai pada Pekerjaan air conditioner Bangunan Gedung Perkantoran terhadap biaya proyek.

Teknik pengumpulan data yang umum digunakan dalam penelitian kuantitatif ada dua, yaitu Metode Survei dan Metode Analisis Studi Kasus. Gambar di bawah ini akan menjelaskan diagram alir proses penelitian ini. Alasan digunakannya value engineering adalah karena membutuhkan inovasi pada salah satu pekerjaannya, untuk melakukan analisis biaya diketahui bahw pekerjaan yang dapat dikembangkan adalah pekerjaan air conditioner. Pada pekerhaan air conditioner ini biaya terlihat kurang efisien, karena dinilai masih dapat memiliki alternatif material komponen yang dapat digunakan.

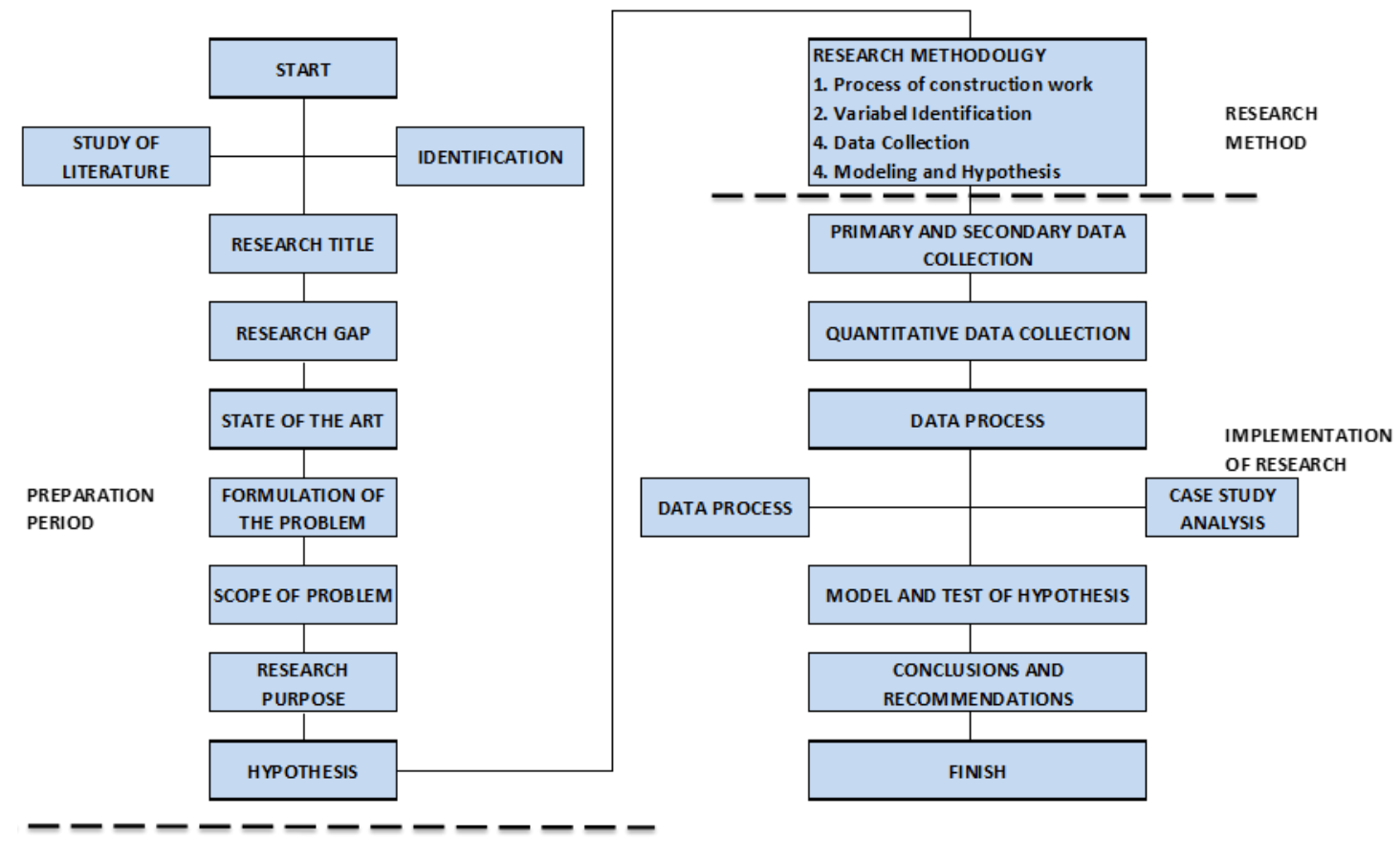

Gambar 2

Detail umum diagram alir fase penelitian rekayasa nilai

Metode Analisis Studi Kasus didefinisikan sebagai penelitiaan yang dilakukan untuk mengetahui akibat yang ditimbulkan dari suatu perlakuan yang diberikan secara sengaja oleh peneliti. Tujuan penelitian eksperimental adalah untuk mengetahui pengaruh 
suatu tindakan yang dilakukan dengan menganalisis data pekerjaan air conditioner pada proyek menggunakan metode rekayasa nilai. Hasil penelitian eksperimental digunakan untuk memprediksi apa yang akan terjadi di masa depan berdasarkan hubungan antar variabel yang telah ditentukan. Penelitian ini akan memfokuskan pada pembahasan studi kasus.

Obyek yang diambil pada penelitian ini adalah Pembangunan Gedung Baru Kantor Pusat Perum LPPNPI di Kota Tangerang. Pada penelitian ini saya membatasi pembahasan pada pekerjaan air conditioner. Melalui penerapan rekasaya nilai yang menggunakan metode atau teknik Rencana Kerja Rekayasa Nilai (Job Plan) berdasarkan teori dari Dell' Isola dalam buku Mohammed Ali Berawi. Kegiatan penelitian ini dibatasi pada tahap implementasi dari sudut pandang pemilik dalam efisiensi biaya.

Data primer dalam penelitian ini adalah proyek yang digunakan untuk pengujian validasi studi kasus yaitu pekerjaan air conditioner pada proyek LPPNPI yang akan dilaksanakan oleh Kontraktor dari PT. Brantas Abipraya, yang diperuntukkan untuk kegiatan perkantoran. Berikut adalah data umum mengenai Proyek yang dilakukan analisis rekayasa nilai: Nama Proyek: Pembangunan Gedung Baru Kantor Pusat LPPNPI, Pemberi Tugas: Perum LPPNPI, Kontraktor Pelaksana: PT. Brantas Abipraya (Persero), Alamat Proyek: Ir. H. Juanda, Neglasari, Karangnyar, Tangerang, 15121, Jenis Kontrak: Harga Tetap Lump Sum, Nilai Kontrak: Rp. 70.782.535.474,26 (termasuk PPN 10\%), Periode Pelaksanaan: 210 (Dua Ratus Sepuluh) hari kalender, Periode Pemeliharaan: 180 (Seratus Delapan Puluh) hari Kalender

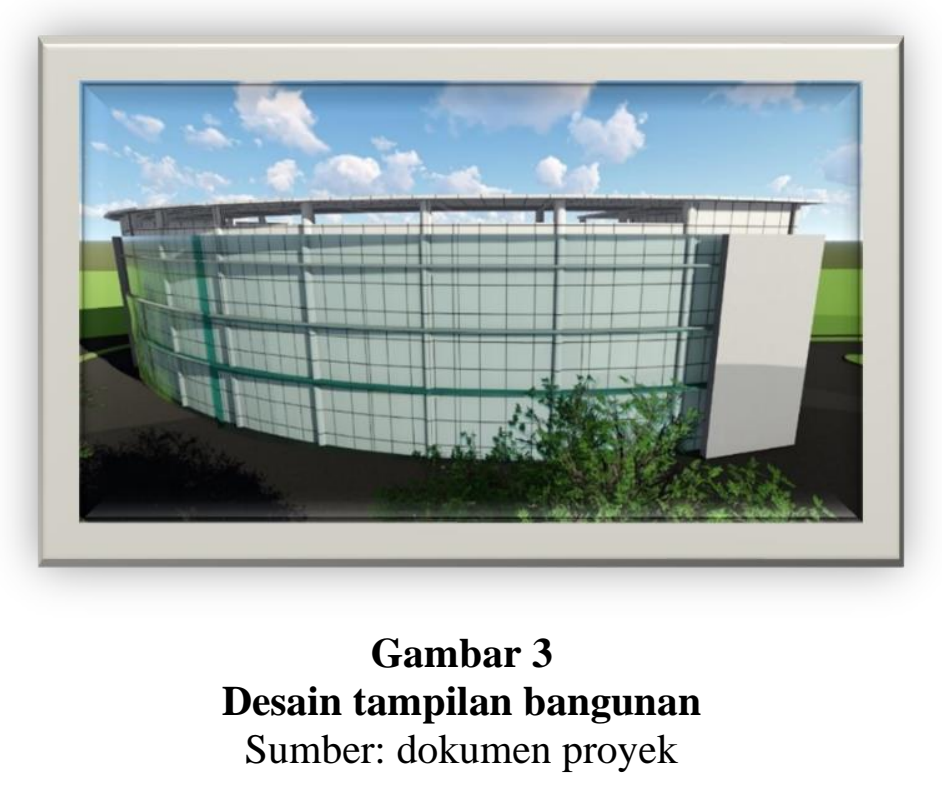

\section{Hasil dan Pembahasan}

\section{A. Model Biaya Awal}

Lingkup pekerjaan pada proyek ini dibagi menjadi 3 bagian besar, yaitu pekerjaan struktur, pekerjaan arsitektur, pekerjaan MEP. Rencana anggaran biaya disusun berdasarkan gambar perencanaan dan spesifikasi bahan serta syarat teknis 
yang sudah ditentukan oleh konsultan perencana. Hingga ditetentukanlah rencana anggran biaya sebagai acuan atau owner estimate:

Tabel 2

RAB Proyek

\begin{tabular}{|c|c|c|c|}
\hline No & Item Pekerjaan & Jumlah Harga & Bobot \\
\hline 1 & Persiapan & $2,782,623,438.00$ & 4.32 \\
\hline 2 & Struktur & $14,794,627,826.26$ & 22.99 \\
\hline 3 & Arsitektur & $17,704,164,548.70$ & 27.51 \\
\hline 4 & MEP & $17,486,304,554.43$ & 27.17 \\
\hline 5 & Furniture & $4,547,763,000.00$ & 7.07 \\
\hline 6 & Interior & $2,249,618,241.60$ & 3.50 \\
\hline \multirow[t]{2}{*}{7} & Penunjang & $4,782,657,911.80$ & 7.43 \\
\hline & Total & $64,347,759,520.79$ & 100.00 \\
\hline
\end{tabular}

Tabel 3

RAB Pekerjaan Mekanikal

\begin{tabular}{llccc}
\hline No & Item Pekerjaan & Jumlah Harga & Bobot & Kumulatif \\
\hline 1 & Air Conditioner & $4,544,147,221.18$ & 71.61 & 100.00 \\
\hline 2 & Plumbing & $746,351,953.20$ & 11.76 & 28.39 \\
\hline 3 & Sprinkler & $740,941,155.90$ & 11.68 & 16.63 \\
\hline 4 & Fire Hydrant & $314,361,582.00$ & 4.95 & 4.95 \\
\hline
\end{tabular}

Sumber: dokumen proyek

\section{B. Studi Rekayasa Nilai}

\section{Analisis Distribusi Pareto}

Melalui Uji Pareto pada biaya proyek dari komponen proyek atau pekerjaan untuk studi rekayasa nilai yang akan dilakukan. Model breakdown cost dapat dilihat sebagai berikut:

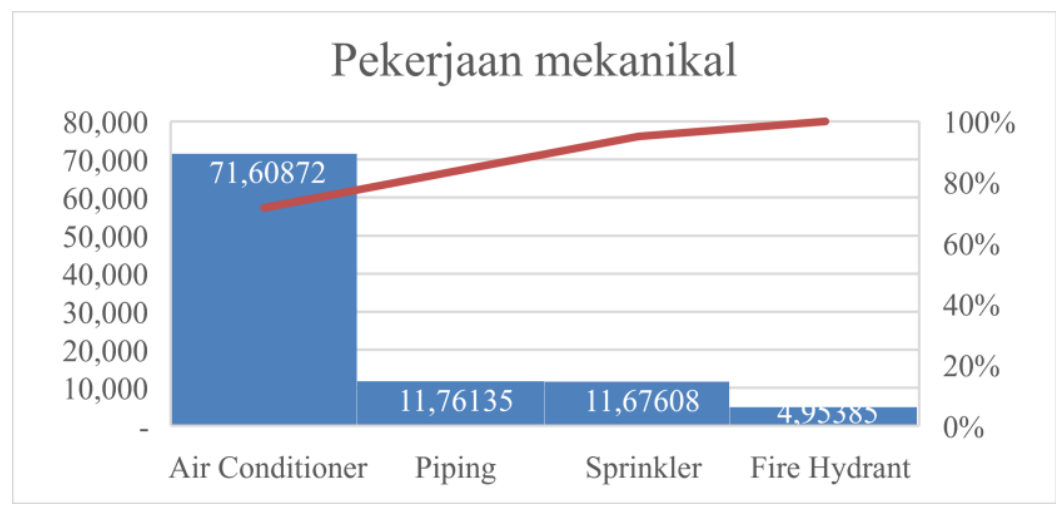

Gambar 4

Diagram Pareto

Sumber: olahan sendiri 
Dari data diatas maka biaya pekerjaan air conditioner memiliki biaya yang paling tinggi, dibandingkan dengan item pekerjaan lainnya seperti plumbing, sprinkler, dan fire hydrant. Oleh karena itu penulis memilih pekerjaan air conditioner untuk dilakukan penelitian.

\section{Tahap Analisis Fungsi}

Analisis fungsi pekerjaan pekerjaan air conditioner pada tahap ini diidentifikasi dari kata kerja aktif dan kata benda. Identifikasi ini dilakukan secara acak kemudian dikelompokkan dan diidentifikasi untuk setiap jenisnya

Tabel 4.

Analisi Fungsi

\begin{tabular}{llll}
\hline Pekerjaan & \multicolumn{3}{c}{ Fungsi } \\
\cline { 2 - 4 } & Kata kerja & Kata benda & Jenis \\
\hline Air Conditioner & Mengatur & Suhu ruangan & Primer \\
\hline & Mengatur & Kelembapan & Sekunder \\
\hline
\end{tabular}

Sumber: olahan sendiri

Fungsi Primer: Fungsi dasar, yaitu fungsi, tujuan, atau prosedur yang menjadi tujuan utama dan harus dijaga, fungsi sekunder: fungsi sekunder merupakan fungsi penunjang yang mungkin dibutuhkan tetapi tidak melaksanakan pekerjaan yang sebenarnya.

3. FAST Diagram Analysis

Dari hasil penyusunan fungsi fungsi dalam technical FAST diagram pada gambar di dapatkan:: (a) keluaran fungsi dasar: efisiensi biaya, pemenuhan konsep hemat energi, (b) fungsi dasar / primer: mengontrol suhu udara, (c) Fungsi petunjuk: memilih jenis air conditioner yang tepat dan memilih desain pemasangan yang tepat, (d) Fungsi penyebab: hemat biaya, (e) Fungsi pendukung: mengatur kelembapan, (f) Desain objek fungsi: untuk selubung bangunan Klasifikasi fungsi item paket air conditioner di atas disusun berdasarkan FAST diagram, seperti pada gambar berikut:

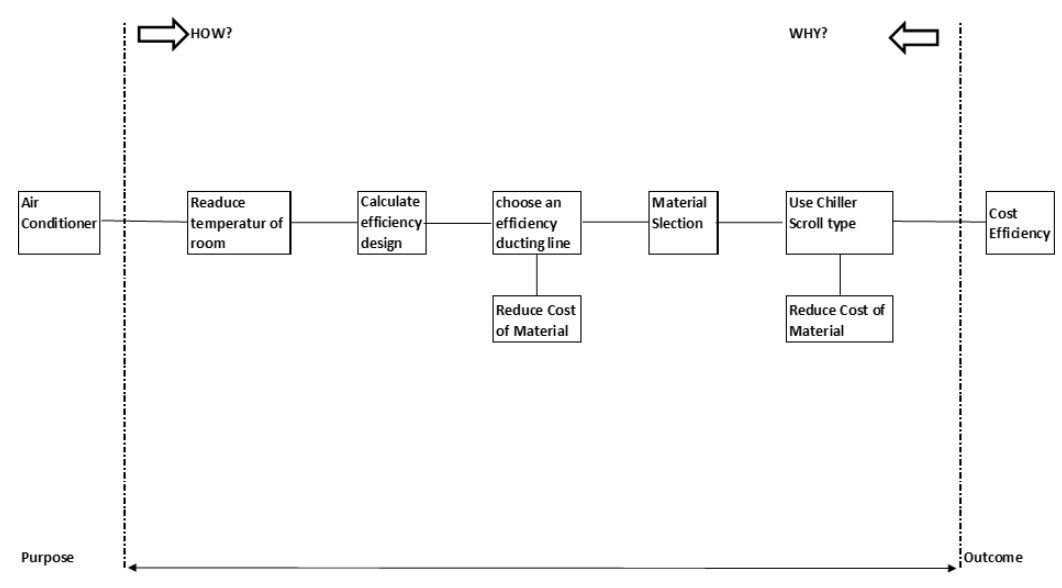

Gambar 5

FAST diagram analysis 
Efisiensi Biaya Pekerjaan Air Conditioner Berbasis Rekayasa Nilai pada Gedung

\section{Cost Worth Analysis}

Rasio biaya manfaat (cost to worth ratio) adalah target akhir yang harus dicapai dalam cost to worth analysis, Berawi (2014) menyatakan rasio biaya manfaat dicari untuk menentukan sistem atau kelompok fungsi yang memiliki peluang bagi perbaikan biaya atau menjadi fokus tim rekayasa nilai

\section{Tabel 5}

Cost worth analysis pekerjaan chiller

\begin{tabular}{|c|c|c|c|c|c|c|}
\hline \multicolumn{7}{|c|}{ Tahap Analisis Fungsi } \\
\hline Item & \multicolumn{4}{|c|}{ Pekerjaan air conditioner } & \multirow[t]{2}{*}{ Keterangan } & $\mathrm{B}=$ Primer \\
\hline Fungsi & \multicolumn{4}{|c|}{ Memompa refrigeran } & & $\mathrm{S}=$ Sekunder \\
\hline \multirow[t]{2}{*}{ No } & Deskripsi & \multicolumn{3}{|c|}{ Fungsi } & \multirow[t]{2}{*}{ Cost } & \multirow[t]{2}{*}{ Worth } \\
\hline & & $\begin{array}{l}\text { Kata } \\
\text { kerja }\end{array}$ & $\begin{array}{c}\text { Kata } \\
\text { benda }\end{array}$ & Jenis & & \\
\hline \multirow[t]{3}{*}{1} & $\begin{array}{c}\text { Pekerjaan } \\
\text { Chiller }\end{array}$ & Mengatur & $\begin{array}{c}\text { Suhu } \\
\text { Ruangan }\end{array}$ & B & $1,750,000,000.00$ & $1,500,000,000.00$ \\
\hline & \multirow{2}{*}{\multicolumn{2}{|c|}{ Cost/Worth Index }} & 1.17 & Persen & $53.85 \%$ & $46.15 \%$ \\
\hline & & & & Deviasi & & $9 \%$ \\
\hline
\end{tabular}

Sumber: olahan sendiri

Tabel 6

Cost of Worth Pekerjaan Ducting

Tahap Analisa Fungsi

\begin{tabular}{|c|c|c|c|c|c|}
\hline Item & Pekerjaan air co & ditioner & & \multirow[t]{2}{*}{ Keterangan } & $\mathrm{B}=$ Primer \\
\hline Fungsi & \multicolumn{3}{|c|}{ Mengalirkan refrigeran } & & $\mathrm{S}=$ Sekunder \\
\hline No & \multicolumn{3}{|c|}{ Fungsi } & Cost & Worth \\
\hline & $\begin{array}{l}\text { Kata } \\
\text { Kerja }\end{array}$ & $\begin{array}{c}\text { Kata } \\
\text { Benda }\end{array}$ & Jenis & & \\
\hline 1 & $\begin{array}{c}\text { Pekerjaan } \mathrm{Me} \\
\text { Ducting }\end{array}$ & Udara & B & $403,442,685.36$ & $336,148,768.80$ \\
\hline \multicolumn{2}{|r|}{ Cost/Worth Index } & 1.20 & Persen & $54.55 \%$ & $45.45 \%$ \\
\hline
\end{tabular}

Sumber: olahan sendiri 


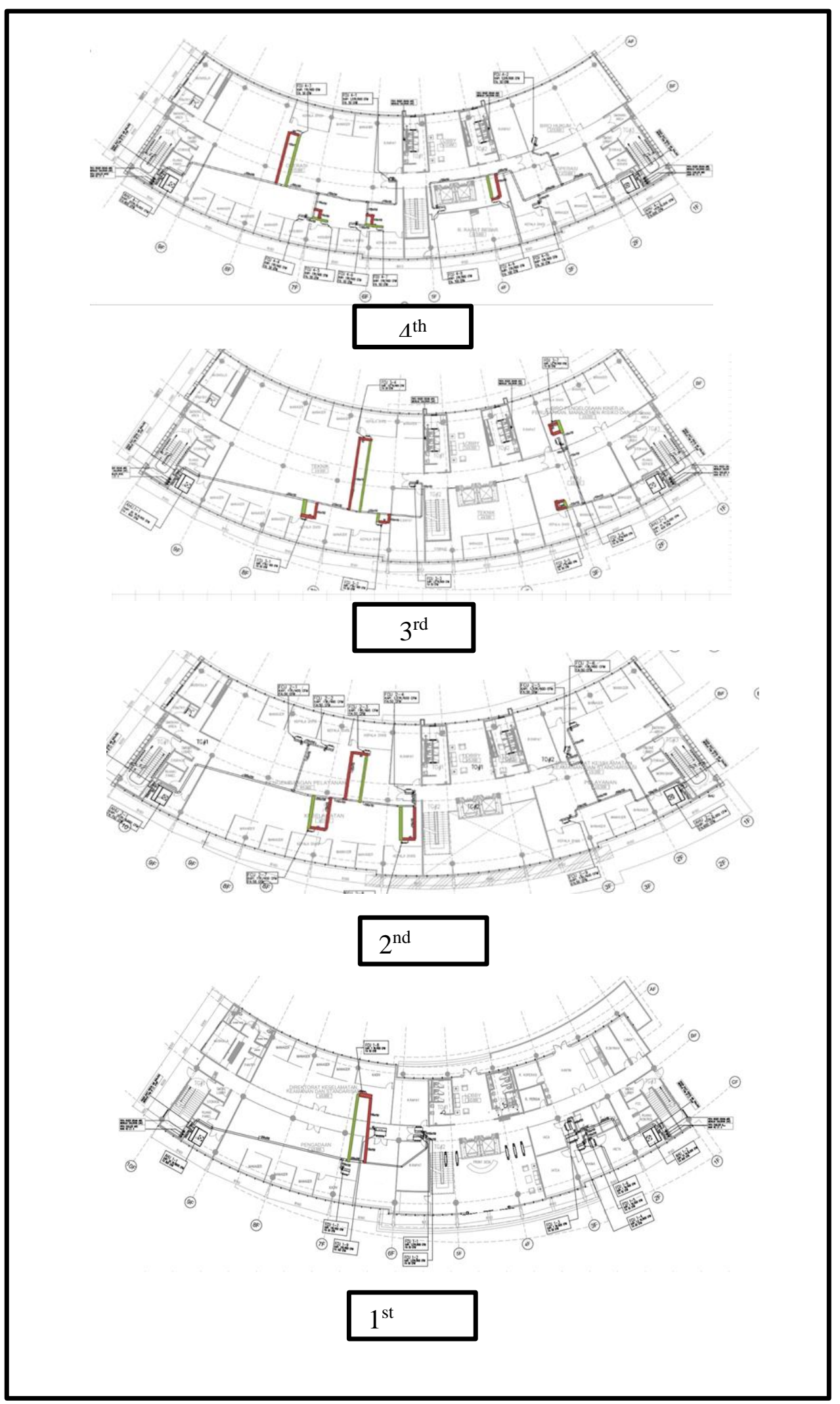

Gambar 6

Rekayasa nilai pekerjaan ducting

Sumber: olahan sendiri 


\section{Tahap kreatif}

Dalam tahap kreatif dikembangkan sejumlah metode alternatif demi tercapainya fungsi dasar. Pertanyaan yang harus dijawab pada tahap ini adalah hal-hal alternatif apa sajakah yang dapat dilakukan untuk menampilkan fungsi. Oleh karena itu, pemahaman permasalahan sangatlah diperlukan untuk memecahkan masalah. Item pada tahap cost worth dirasa cukup tinggi perlu menjadi fokus dalam memilih alternatif penggantinya.

Tabel 7

Tahap Kreatif Pada Pekejaan Chiller

Tahap kreatif

\begin{tabular}{ll}
\hline \multicolumn{2}{l}{ Pengumpulan alternatif } \\
\hline Item: Chiller & \\
\hline No & Alternatif \\
\hline 1 & Pekerjaan chiller memaikai type Scroll \\
\hline & Sumber: olahan sendiri
\end{tabular}

\section{Tahap Evaluasi}

Tahapan selanjutnya adalah keuntungan dan kerugian masing-masing ide kreatif dicatat, kemudian masing-masing alternatif diberi peringkat (rating). Pemberian rangking ini bertujuan untuk mengklasifikasikan alternatif-alternatif sesuai urutan keuntungan dan kerugiannya. Alternatif dengan rangking tertinggi ditunjukkan dengan pemberian angka terkecil, yaitu menunjukkan bahwa alternatif pada perhitungan rekayasa nilai dalam memilih alternatif terbaik dapat dimunculkan kriteria-kriteria dari item pekerjaan air conditioner. Kriteria tersebut merupakan komponen-komponen dalam desain dan pelaksanaan terhadap pekerjaan arsitektur. Keuntungan dan kerugian dari penambahan pada pekerjaan air conditioner, dapat dilihat pada tabel-tabel berikut ini :

Tabel 8.

Tahap Kreatif Pada Pekejaan Chiller

\begin{tabular}{l}
\hline \multicolumn{1}{c}{ Keuntungan } \\
\hline Biaya lebih murah \\
\hline Operasi yang tidak ribut \\
\hline Getaran sangat rendah \\
\hline Proses kompresi terus menerus dengan \\
hamper tidak ada getaran \\
\hline Terbukti tahan (tahan rusak) \\
\hline Sangat sedikit bagian yang bergerak \\
\hline \begin{tabular}{l} 
Proses kompresi yang berkelanjutan \\
tanpa getaran atau guncangan \\
\hline Tidak bermasalah dengan desain \\
(dimana tidak bersentuhan diantara
\end{tabular}
\end{tabular}


scroll), gesekan yang sangat kecil yang

mana menigkatkan efisiensi

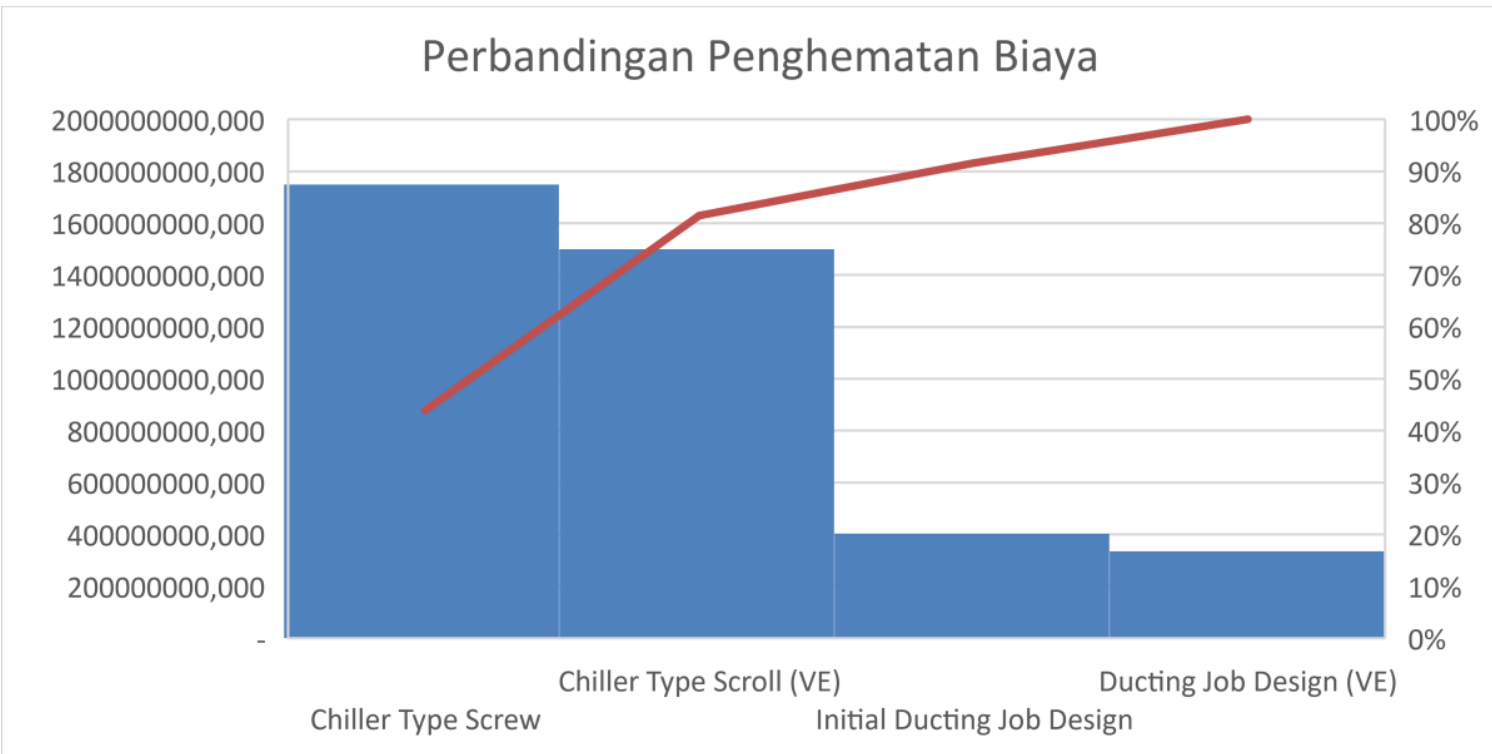

Gambar 7

Perbandingan efisiensi biaya

Sumber: olahan sendiri

\section{Tahap Pengembangan}

Pada tahap pengembangan, alternatif yang terpilih dari tahap sebelumnya dihitung biayanya, kemudian dibandingkan biaya design alternative dengan desain awal proyek. Adapun perbandingan biaya desain awal dengan Rekayasa Nilai lihat tabel berikut ini:

\section{Tabel 9}

RAB Pekerjaan Chiller dan Ducting

\begin{tabular}{|c|c|}
\hline Item Pekerjaan & Total Biaya \\
\hline Pekerjaan Chiller & $1,500,000,000.00$ \\
\hline $\begin{array}{ll}\text { Pekerjaan } & \text { Line } \\
\text { Ducting } & \end{array}$ & $336,148,768.80$ \\
\hline Total & $1,836,148,768.80$ \\
\hline
\end{tabular}

Sumber: olahan sendiri

Tabel 10

Perbandingan RAB Sebelum dan Sesudah VE

\begin{tabular}{lcccc}
\hline \multicolumn{1}{c}{$\begin{array}{c}\text { Uraian } \\
\text { Pekerjaan }\end{array}$} & Harga Awal & $\begin{array}{c}\text { Harga Setelah } \\
\text { VE }\end{array}$ & Efisiensi & \% \\
\hline Pekerjaan Chiller & $1,750,000,000.00$ & $1,500,000,000.00$ & $250,000,000.00$ & $14.29 \%$ \\
\hline $\begin{array}{l}\text { Pekerjaan Line } \\
\text { Ducting }\end{array}$ & $403,442,685.36$ & $336,148,768.80$ & $67,293,916.56$ & $16.68 \%$ \\
\hline Total & $2,153,442,685.36$ & $1,836,148,768.80$ & $317,293,916.56$ & $14.73 \%$ \\
\hline \multicolumn{5}{c}{ Sumber: olahan sendiri }
\end{tabular}




\section{Tahap Rekomendasi}

Tahap ini adalah tahap terakhir proses rekayasa nilai, yang terdiri dari persiapan dan penyajian kesimpulan rekayasa nilai kepada yang berkepentingan. Laporan hanya mengetengahkan fakta dan informasi untuk mendukung argumentasi. Semua variasi aspek teknis dan biaya desain semua dibandingkan dengan hasil Rekayasa Nilai dipaparkan dengan jelas. Tahap rekomendasi juga merupakan proses mengajukan ide terbaik yang diusulkan untuk bisa diterima dan dilaksanakan untuk pemilik. Rekomendasi bisa mengubah desain dan penghematan menjadi salah satu ukuran bahwa usulan tersebut bisa diterima. Dalam tahap rekomendasi disajikan keistemewaan dan keunggulan konsep dari usulan desain baru yang bisa menjadi dasar alasan bagi pemilik untuk menerima perubahan. Jadi laporan akhir akan berisikan data sebagai berikut

Tabel 11

Usulan pekerjaan air conditioner

\begin{tabular}{lcc}
\hline \multicolumn{1}{c}{ Kriteria } & Kondisi Awal & Alternatif VE \\
\hline Pekerjaan Chiller & Type Screw & Type Scroll (VE) \\
\hline $\begin{array}{l}\text { Pekerjaan } \\
\text { Ducting }\end{array}$ & Desain awal & Desain (VE) \\
\hline Biaya & $2,153,442,685.36$ & $1,836,148,768.80$ \\
\hline Efisiensi & $317,293,916.56$ \\
\hline Efisiensi (\%) & \multicolumn{2}{c}{$14.73 \%$} \\
\hline \multicolumn{3}{c}{ Sumber: olahan sendiri }
\end{tabular}

\section{Kesimpulan}

Dari hasil penelitian, penerapan nilai engineering pada pekerjaan pengkondisian udara atau air conditioner dapat menurunkan biaya sebesar $14,73 \%$ dari biaya awal. Untuk penelitian lebih lanjut dilakukan untuk mengembangkan penerapan nilai-nilai teknik pada air conditioner lainnya. Penelitian selanjutnya juga dapat dikembangkan dengan menggabungkan hasil implementasi di lapangan dengan mengukur tingkat kualitas hingga implementasi. Berdasarkan hasil perhitungan LCC yang dimilikinya. Terbukti bahwa penggantian komponen dan desain air conditioner mempengaruhi efektivitas biaya. 


\section{BIBLIOGRAFI}

Ariadi. (2017). Faktor Kunci Sukses Penerapan Value Engineering (Ve) Pada Bangunan Gedung Di Indonesia. Rekayasa Sipil, 6(2), 77-85. Google Scholar

Berawi, M. A., Susantono, B., Miraj, P., Berawi, A. R. B., Rahman, H. Z., Gunawan, \& Husin, A. (2014). Enhancing Value for Money of Mega Infrastructure Projects Development Using Value Engineering Method. Procedia Technology, 16, 10371046. https://doi.org/10.1016/j.protcy.2014.10.058. Google Scholar

Che Mat. (2004). Value Management - The Way Forward. Google Scholar

Husin, A. E. (2015). Model Aliansi Strategis Dalam Kemitraan Pemerintah dan Swasta Pada Mega Proyek Infrastruktur Berbasis Value Engineering untuk Meningkatkan Nilai Kelayakan Proyek. Google Scholar

Isola, D. (1997). Value Engineering Practical Applications for Design Construction Maintenance \& Operations. Google Scholar

Marzuki. (2006). Value Analysis Technique and General Electric Company for Value Enhancement Studies. Google Scholar

Prasetio, H. E., Malkhamah, S., Watson, C., \& Subarmono, S. (2017). Comparative Study on Implementing Home Air Conditioning for Passenger Carriages in the Indonesian Railway. Journal of the Civil Engineering Forum, 3(3), 175. https://doi.org/10.22146/jcef.27820 Google Scholar

Priyanto, S., Suharno, H., \& Haryono, H. (2017). Value Engineering Dan Strategi Bisnis Pada Pt Angkasa Pura Ii. Jurnal Manajemen Transportasi Dan Logistik, 3(2), 245. https://doi.org/10.25292/j.mtl.v3i2.104. Google Scholar

Qiping Shen, G. L. (2003). Critical success factors for knowledge management studies in construction. 2006 Proceedings of the 23rd International Symposium on Robotics and Automation in Construction, ISARC 2006, October, 768-772. https://doi.org/10.22260/isarc2006/0142 Google Scholar

SAVE Standard. (2008). Certification Examination Study Guide. 3404(April), 1-2. Google Scholar

Salamadian. (2020). Air Conditioner, https://salamadian.com (Feb. 5, 2020). Google Scholar

Sugiyono. (2013). Metode Penelitian Kuantitatif, Kualitatif dan R\&D. Bandung. Alfabeta Google Scholar

Thoengsal. (2014). Value Engineering ( Rekayasa Nilai ). Google Scholar

Untoro. (2009). Penerapan Value Engineering Dalam Penyelenggaraan Infrastruktur 
Bidang Dalam Penyelenggaraan Infrastruktur Bidang Ke-Pu-an Di Lingkungan. Google Scholar

Zimmerman, H. (1982). Value Engineering A Practical Approach for Owners, Designers, and Contractors. Google Scholar

\section{Copyright holder:}

Gian Fahmi Pangestu dan Humiras Hardi Purba (2021)

First publication right:

Journal Syntax Literate

This article is licensed under:

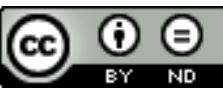

